\title{
Interação e linguagem nos fóruns das licenciaturas a distância da UFSC/UAB
}

\author{
Dulce Márcia Cruz. PPGE/UFSC. dulce.marcia@gmail.com \\ Mônica Cristina Dutra Grumiché. PPGE/UFSC. mogrumiche@ hotmail.com
}

\section{RESUMO}

A pesquisa aqui relatada objetivou investigar possíveis mudanças nos processos comunicacionais da função docente na Educação a Distância, verificadas nos textos de diferentes mídias utilizadas na modalidade. Foram investigadas cinco disciplinas de um curso de Licenciatura da UAB/UFSC ofertadas em dois momentos: um 2008-1 e outro em 2009-2. O intento foi o de perceber mudanças nas disciplinas em termos de integração dos diversos materiais didáticos (impressos, digitais e audiovisuais) e a participação dos agentes registrada no ambiente virtual de ensino e aprendizagem (AVEA). Os resultados apontaram que das ferramentas à disposição neste formato educativo a mais utilizada é o fórum. E que a interação com os alunos é realizada pelo tutor enquanto o professor parece estar cada vez mais distante da relação com o aluno, ao menos em termos de presença escrita via AVEA. Ainda foi possível inferir que houve progressos quanto à participação discente dentro do AVEA, pois, em termos comparativos, os alunos em 2009-1 quantitativamente participaram em maior número que em 2008-1.

Palavras-chave: educação a distância, mediação pedagógica, tutoria.

\begin{abstract}
The research reported here aimed to investigate possible changes in the communicational processes of the teaching function in Distance Education, found in texts of different media used in the modality. We investigated five disciplines of a degree course at the UAB / UFSC offered in two periods: 2008-1 and another one in 2009-2. The intent was to see changes in the subjects in terms of integration of the various materials (printed, digital and audiovisual) and the participation of agents registered in the virtual environment for teaching and learning (AVEA). The results showed that between the tools available in this educational format the most used is the forum. And the interaction with students is conducted by tutor while the teacher seems to be increasingly distant in the relationship with the student, at least in terms of the written via AVEA. It is possible to infer that there was progress in student participation in the AVEA because, comparatively speaking, students in 2009-1 quantitatively participated in greater numbers than in 2008-1.
\end{abstract}

Keywords: distance education, pedagogical mediation, mentoring.

\section{INTRODUÇÃO}

No século XXI, a educação a distância (EaD) aparece cada vez mais como uma modalidade capaz de atender às novas demandas educacionais, decorrentes da atual ordem econômica mundial. A modalidade a distância de educação se caracteriza por um afastamento de tempo e espaço entre alunos e professores, o diálogo entre eles ocorre em grande parte pelo uso intensivo de tecnologias da informação e comunicação.

Essas peculiaridades incutem mudanças especiais na ação de todos os envolvidos. Quanto à ação docente, na EaD ela "não é exercida por um único professor, 
mas por uma equipe, que tem como objetivo principal avaliar e reorientar as estratégias de ensino e favorecer a aprendizagem dos alunos” (UFSC, 2009, p. 33). Assim, os professores, tutores, designers instrucionais, coordenadores e outros profissionais da $\mathrm{EaD}$ formam um grupo no qual precisa haver uma integração quanto a responsabilidades com as tarefas necessárias para que seja possível o bom andamento de um curso.

Desde 2007, a Universidade Federal de Santa Catarina (UFSC) participa da oferta de cursos a distância da Universidade Aberta do Brasil (UAB), criada pelo governo federal em 2006. Os profissionais envolvidos nesse processo e que atuam diretamente junto aos estudantes quanto ao ensino-aprendizagem da UAB/UFSC, são os professores e os tutores. Há duas possibilidades de atuação tutorial: à distância e presencial. Os tutores à distância são aqueles que atuam na UFSC e interagem com os alunos exclusivamente por meio das mídias digitais. Enquanto que os tutores presenciais atuam diretamente nos pólos de aprendizagem, local freqüentado pelos alunos.

Para esse modelo cabe ao professor planejar e desenvolver as atividades para o processo de ensino-aprendizagem e organizá-las em um plano de ensino; participar da escolha dos tutores UFSC para a sua disciplina; acompanhar com os tutores a aprendizagem dos estudantes; realizar encontros presenciais viajando ao pólo ou realizar aulas por videoconferência; agendar horários de atendimento aos estudantes por meio das mídias; elaborar e corrigir avaliações junto com os tutores; etc.

Já aos tutores, sejam a distância (UFSC) ou presenciais (Pólo), lhes cabem as responsabilidades e atividades de mediarem as relações entre professores, estudantes e instituição; ocuparem papel central para o ensino de aprendizagem, principalmente por manter um contato constante com os estudantes, esclarecendo dúvidas, ajudando-os e motivando-os a organizarem seus tempos de estudos; acompanharem suas atividades, orientando, e realizando feedbacks nos processos de avaliação (Cruz, 2010).

As características da $\mathrm{EaD}$ sugerem ações diferenciadas de todos os envolvidos no processo. Aos alunos grande responsabilidade, a de se tornarem estudantes autônomos, sujeitos centrais no seu processo de ensino-aprendizagem. Quanto à atuação dos professores e tutores, são necessários saberes que lhes permitam interagir em ambientes virtuais de ensino e aprendizagem (AVEA) em articulação aos saberes específicos da área de conhecimento que estão mediando.

Belloni (1999, p. 54) afirma que "a educação é e sempre foi um processo complexo que utiliza a mediação de algum tipo de meio de comunicação como complemento ou apoio à ação do professor em sua integração pessoal e direta com os estudantes", no processo a distância, há uma grande dependência dessa mediação porque ela é realizada pela combinação dos mais variados suportes técnicos de comunicação. Isso porque essa "integração entre o professor e o estudante ocorre de modo indireto no espaço (à distância, descontínua) e no tempo (comunicação deferida, não simultânea) o que acrescenta complexidade ao já bastante complexo processo de ensino e aprendizagem na EaD” (Belloni, 1999, p 54).

Nesse processo, o fato do tutor se responsabilizar pelo diálogo e acompanhamento constante dos estudantes, leva ao questionamento se ele também é professor ou se sua função se caracteriza como mediação pedagógica. Segundo Mill et $a l$, o "docente-tutor" não é exatamente um professor, mas um responsável pela mediação pedagógica independente do termo que recebe.

O que caracteriza este trabalhador é sua função de acompanhar os alunos no processo de aprendizagem, que se dá, na verdade, pela intensa mediação tecnológica. $\mathrm{O}$ docente-tutor participa do ensino-aprendizagem mais como 
um mediador e motivador na relação do aluno com material didático, em busca do conhecimento. Independentemente da denominação que recebe, esse tutor é responsável pela mediação pedagógica da construção do saber de seus alunos. (Mill et al, 2008, p.115)

Trabalhando neste contexto, nossas pesquisas têm visado perceber como os agentes formativos (especialmente professores e tutores) estão compreendendo os desafios que as mídias trazem em suas rotinas de trabalho, se estão aprendendo suas linguagens e se vêm utilizando-as de maneira dialógica na educação a distância.

No universo dos cursos de licenciatura a distância da UAB/UFSC já investigamos a comunicação ocorrida nas disciplinas de Introdução a $\mathrm{EaD}$ (CRUZ; MARTINS, 2008) e entrevistamos e acompanhamos professores e analisamos seu trabalho nas diversas mídias dos cursos. No decorrer das pesquisas fizemos a escolha de focar nossa atenção nos tutores, tentando verificar de que maneira essa função criada pela educação a distância, vem desenvolvendo as atividades de apoio no modelo UAB. Observamos que, para além das funções tutoriais, há um trabalho de docência cada vez mais intenso e freqüente sendo realizado por esses agentes.

Nosso lócus de pesquisa foram os ambientes virtuais dos cursos de licenciatura da UAB/UFSC. Na pesquisa do semestre 2008-1, pelos resultados de questionários aplicados e pela investigação quantitativa dos ambientes virtuais percebemos que a responsabilidade dos tutores com relação às tarefas docentes, parecia maior do que era determinado nos guias de atuação, especialmente por parte dos que estão a distância, na UFSC. Essas tarefas se dão primordialmente pelo atendimento nos chats e, de forma mais aprofundada e freqüente, nos fóruns de discussão. Dessa maneira, pensamos que um espaço privilegiado para compreender os processos de ensino-aprendizagem na EaD/UFSC é o espaço virtual, o Moodle, e nele, mais especificamente, os fóruns de discussão. Por essa razão, tentando verificar de que maneira esse trabalho vem acontecendo, especificamos nossos estudos sobre os fóruns de discussão dos cursos de licenciatura a distância da UAB/UFSC.

\section{MATERIAIS E MÉTODOS}

A metodologia adotada contemplou uma revisão da literatura; a compilação e arquivamento de documentos (manuais, formulários, questionários, apresentações em Power Point e todo tipo de informação oferecida sobre as temáticas: EaD; formação docente; linguagem e comunicação; e mediação pedagógica); a compilação e arquivamento de materiais impressos (os livros didáticos escritos pelos professores, os guias de alunos, tutores e professores), os materiais preparados para o ambiente virtual de ensino e aprendizagem (as disciplinas colocadas dentro do AVEA, roteiros e material didático preparado pelos professores para a aula pela videoconferência, bem como as aulas transmitidas, etc.), buscando criar um banco de textos variados.

Na primeira edição da pesquisa em 2008-1 investigamos a relação entre os materiais didáticos de dois cursos de licenciatura. O parâmetro para a escolha da amostra foi o número de pólos, com o objetivo de tentar responder a seguinte questão: será que a quantidade de pólos envolvidos na execução de cada disciplina interfere na formatação comunicacional desenvolvida no curso? $\mathrm{Na}$ investigação junto aos cursos selecionados, encontramos semelhanças e diferenças que permitiram afirmar que a quantidade de pólos não interferia no formato do desenho, no uso das ferramentas e no modo que a comunicação ocorria nas disciplinas. Pelo contrário, no curso onde muitos pólos estavam envolvidos, a preocupação com a organização do curso pareceu tamanha 
que a participação dos estudantes e tutores permaneceu constante durante todo o percurso do semestre. No entanto, ficou claro que quanto maior o número de pólos, menor é a troca estabelecida diretamente entre professores (responsáveis pela disciplina) e estudantes e que a mediação pedagógica ocorre quase que exclusivamente pelo trabalho dos tutores.

Com a reedição de um dos cursos, que na nossa pesquisa só possuía um pólo, e que na nova versão foi oferecido em quatro pólos em 2009-2, percebemos que teríamos a chance de investigar melhor essa relação. Por essa razão, reaplicamos a mesma metodologia de coleta e análise quantitativa para o primeiro semestre do curso, que teve as mesmas cinco disciplinas investigadas anteriormente e em quatro delas, os mesmos professores. Isso gerou uma amostra de professores que tiveram pelo menos dois semestres de experiência com uma mesma disciplina. Em termos de apropriação midiática poderíamos verificar se houve aprendizagem, modificações ou melhorias. É preciso ressaltar que, para a reedição em quatro pólos, os materiais didáticos foram revisados, os ambientes virtuais refeitos e houve um acréscimo no número de tutores, que passaram de um para quatro por disciplina, para atender ao modelo da UAB que exige que um tutor deve ser responsável pela mediação de, no máximo, 50 alunos. Neste caso, ficou determinado que um tutor ficaria responsável por cada pólo envolvido.

Um sistema de educação a distância exige que o professor e o tutor conheçam o contexto e a realidade do seu estudante, as suas necessidades, limitações e capacidades para melhor poder ajudá-lo. Para isso, professores e tutores têm à disposição ferramentas de comunicação como o chat, fórum, videoconferência e correio eletrônico para assim realizar uma aproximação como os integrantes do curso. O "Guia dos tutores UAB/UFSC" define o fórum como "uma ferramenta de troca de mensagens em grupos, organizada por assuntos e registradas no ambiente" (UFSC, 2009, p.30). Tópicos fazem parte do material disponibilizado no ambiente virtual que vai agregar "conteúdos complementares decorrentes dos capítulos do material impresso da disciplina", podendo ter por base um ou mais capítulos do livro texto (UFSC, 2009, p.41).

Da mesma maneira que em 2008-1, os itens coletados no AVEA no curso oferecido em 2009-2 foram referentes aos seguintes temas: apresentação; tópicos; tipos e quantidade de fóruns; número de postagens. Também verificamos o uso do chat, da videoconferência e da vídeo-aula em algumas disciplinas (CRUZ; GRUMICHÉ; SILVA, 2010). A compilação e arquivamento de materiais digitais realizados no Moodle buscaram responder algumas questões: Como são transpostos os conhecimentos construídos durante os encontros presenciais para o meio virtual? Existe essa preocupação? Como são as interações realizadas pelos tutores? (Quantidade, qualidade e análise da suposta eficácia). Tembém levantamos de forma quantitativa: Relação AVEA e Livro; Tópicos criados no AVEA (curso como um todo); Fóruns (tipos, quantidade, assuntos, quem criou, quantidade de acessos gerais e por categoria); Chats (organização, quantidade, assuntos).

\section{RESULTADOS E DISCUSSÕES}

\subsection{A apresentação do AVEA}

O primeiro item analisado foi a apresentação dos professores e tutores no AVEA. Na "Tabela 1" vemos uma comparação entre os dois semestres pesquisados. 
Tabela 1: Apresentação da disciplina no AVEA

\begin{tabular}{|c|c|c|}
\hline Disciplina & 2008-1 & 2009-2 \\
\hline 1 & $\begin{array}{l}\text { Professores e tutores são apresentados por } \\
\text { fotos, e uma professora também por vídeo } \\
\text { que se apresenta e fala da disciplina. }\end{array}$ & $\begin{array}{l}\text { Os dois professores e tutores são } \\
\text { apresentados apenas por fotos e é possível } \\
\text { ler sobre eles nos seus perfis. }\end{array}$ \\
\hline 2 & $\begin{array}{l}\text { Tutor Pólo não aparece no AVEA. } \\
\text { Professor e tutora UFSC apresentam-se } \\
\text { com fotos e vídeos. }\end{array}$ & $\begin{array}{l}\text { A apresentação ocorre por fotos de todos e } \\
\text { vídeo apenas do professor que fala da } \\
\text { disciplina e sobre o semestre de aulas. }\end{array}$ \\
\hline 3 & $\begin{array}{l}\text { Professor e tutora UFSC têm foto. O } \\
\text { espaço destinado ao Tutor Pólo aparece, } \\
\text { mas não foi preenchido. O mural dá boas- } \\
\text { vindas ao grupo e apresenta um } \\
\text { cronograma com as principais datas do } \\
\text { curso. }\end{array}$ & $\begin{array}{l}\text { A apresentação se dá apenas por fotos e } \\
\text { pelo histórico escrito por cada um no } \\
\text { perfil. }\end{array}$ \\
\hline 4 & $\begin{array}{l}\text { Professor e tutora UFSC têm foto. O } \\
\text { espaço destinado ao Tutor Pólo aparece, } \\
\text { mas não foi preenchido. O mural informa } \\
\text { as últimas notícias ocorridas. }\end{array}$ & $\begin{array}{l}\text { Os tutores são apresentados por fotos e há } \\
\text { o vídeo do professor que se apresenta e } \\
\text { fala da disciplina. }\end{array}$ \\
\hline 5 & $\begin{array}{l}\text { Não tem apresentação permanente do } \\
\text { professor e tutores. O Mural relata as } \\
\text { últimas notícias e tarefas a serem } \\
\text { executadas. }\end{array}$ & $\begin{array}{l}\text { Fotos e pelo histórico escrito por cada um } \\
\text { no seu perfil. }\end{array}$ \\
\hline
\end{tabular}

$\mathrm{Na}$ "Disciplina 1", o vídeo é utilizado por dois professores tanto na primeira quanto na segunda edição, mas em disciplinas diferentes o mesmo não acontece, mostrando uma variação de um ano para o outro. Em 2008-1, chama atenção na primeira edição do curso a ausência da foto do tutor pólo, que mesmo possuindo lugar para se apresentar no AVEA não se incorporou na equipe. Isso pode indicar por um lado a percepção de que não há necessidade de se apresentar, já que os alunos estão presencialmente ali para conhecê-los, mas por outro, é um indicativo da pouca atuação do tutor pólo nas atividades do AVEA. Na segunda edição, há mais uso de fotos e perfis como espaço de informação detalhados.

$\mathrm{Na}$ relação entre o AVEA e os livros didáticos escritos pelos professores, buscamos identificar se o primeiro seguia a mesma seqüência didática e mesmos conteúdos que o impresso. De modo geral percebemos que o livro texto ainda é a base e a referência principal tanto em termos de conteúdo como para a seqüência e formato das informações (como capítulos em forma de tópicos), e apenas uma disciplina não segue a ordem do livro. Em algumas há referência a outras fontes e atividades complementares e uma traz um questionário. Apenas uma disciplina traz uma vídeo-aula. Na "Tabela 2" vemos a comparação deste conteúdo.

Tabela 2 - Relação AVEA e Livro

\begin{tabular}{|c|l|l|}
\hline Disciplina & \multicolumn{1}{|c|}{ 2008-1 } & \multicolumn{1}{|c|}{ 2009-2 } \\
\hline $\mathbf{1}$ & $\begin{array}{l}\text { Relação próxima. Remete à leitura do } \\
\text { livro. Ordenada na mesma seqüência e } \\
\text { quantidade de conteúdos dispostos no } \\
\text { livro. }\end{array}$ & $\begin{array}{l}\text { Relação próxima. Remete à leitura dos } \\
\text { capítulos do livro texto, na mesma ordem e } \\
\text { quantidade do livro. }\end{array}$ \\
\hline $\mathbf{2}$ & $\begin{array}{l}\text { Relação próxima, mas não se limita aos } \\
\text { conteúdos do livro. Remete à leitura do } \\
\text { livro e outras atividades obrigatórias para } \\
\text { avaliação, como assistir filmes, resenhas e } \\
\text { textos. }\end{array}$ & $\begin{array}{l}\text { Relação próxima. Remete à leitura dos } \\
\text { capítulos, porém não segue a mesma } \\
\text { seqüência e também não usa somente o } \\
\text { livro, mas sugere outras referências. }\end{array}$ \\
\hline $\mathbf{3}$ & $\begin{array}{l}\text { Segue a ordem do livro, tópicos e capítulos } \\
\text { são os mesmos. Remete à leitura do livro, } \\
\text { destaca e explica as atividades que serão } \\
\text { realizadas no corpo do texto. }\end{array}$ & $\begin{array}{l}\text { Segue a ordem do livro, tópicos e capítulos } \\
\text { são os mesmos. Remete à leitura do livro e } \\
\text { de atividades complementares em outras } \\
\text { fontes. } \\
\text { No AVEA disponibiliza }\end{array}$ \\
\hline
\end{tabular}




\begin{tabular}{|c|l|l|}
\hline & & questionário a ser respondido. \\
\hline $\mathbf{4}$ & $\begin{array}{l}\text { Inicia seguindo a mesma ordem do livro, } \\
\text { mas interrompe no sexto capítulo. Remete } \\
\text { à leitura do livro disponibiliza uma } \\
\text { vídeo-aula no primeiro tópico. }\end{array}$ & $\begin{array}{l}\text { Segue a mesma sequiência dos capítulos, } \\
\text { porém alteram-se os títulos e apresenta o } \\
\text { conteúdo de forma resumida. }\end{array}$ \\
\hline $\mathbf{5}$ & $\begin{array}{l}\text { Relação próxima, mas não se limita aos } \\
\text { conteúdos do livro. Remete à leitura do } \\
\text { livro e outras atividades obrigatórias para } \\
\text { avaliação. }\end{array}$ & $\begin{array}{l}\text { Relação próxima. Porém não se limita } \\
\text { apenas ao livro e nem segue a mesma } \\
\text { sequêencia deste. }\end{array}$ \\
\hline
\end{tabular}

\subsection{Tópicos e Fóruns}

A relação direta com o livro se mostra mais visível quando olhamos os tópicos criados nas disciplinas. Tópicos neste caso se referem ao formato de distribuição do conteúdo em seqüência e em espaços distantes, geograficamente dividindo a tela do Moodle em blocos seqüenciais. O Moodle permite outros formatos, mas a divisão em tópicos é a mais comum nas disciplinas da UAB/UFSC, já que a outras maneiras requerem mais conhecimento técnico do AVEA. E também porque, como vimos, a relação capítulo/tópico parece ser vista como mais fácil de compreensão para conduzir a disciplina, tanto que percebemos uma tendência de seguir os títulos e nomenclaturas que estão dispostos no livro-texto. Nossa hipótese é de que pelo livro desempenhar papel de "guia" tanto para o professor como para o aluno, esse seria o caminho mais fácil de apresentar e orientar o estudo dos conteúdos no AVEA. Em 2009-2, o número de tópicos criados no AVEA variou de disciplina para disciplina. $\mathrm{Na}$ "Disciplina 1" e na "Disciplina 3", vemos que não houve mudança de uma oferta para outra, enquanto nas outras houve uma variação. É importante ressaltar que a "Disciplina 5" foi a única que mudou o professor, as outras são os mesmos docentes, o que pode indicar que os professores das "Disciplina 2" e "Disciplina 4" tentaram variar o formato de apresentação no AVEA e incluir outros aspectos na reedição. Na "Tabela 3" vemos uma comparação entre os semestres pesquisados.

Tabela 3 - Tópicos criados no AVEA

\begin{tabular}{|c|c|c|}
\hline Disciplina & 2008-1 & 2009-2 \\
\hline 1 & $\begin{array}{l}\text { Foram criados seis tópicos igualmente ao } \\
\text { livro, mas a nomenclatura adotada não foi } \\
\text { a mesma. No livro são os conteúdos que } \\
\text { intitulam os tópicos, no AVEA eles são } \\
\text { apenas numerados. }\end{array}$ & $\begin{array}{l}\text { Foram criados seis tópicos, iguais ao livro, } \\
\text { mas a nomenclatura adotada não foi a } \\
\text { mesma. No livro os conteúdos são } \\
\text { apresentados por títulos e no AVEA são } \\
\text { apenas numerados. }\end{array}$ \\
\hline 2 & $\begin{array}{l}\text { Foram criados quatro tópicos, diferente do } \\
\text { livro que possui seis capítulos organizados } \\
\text { em duas partes. A ordem se assemelha a } \\
\text { do livro, mas aglomera algumas unidades } \\
\text { em um único tópico. Utiliza um tópico } \\
\text { especial, sem titulação específica para uma } \\
\text { avaliação de uma atividade tratada } \\
\text { exclusivamente no AVEA. }\end{array}$ & $\begin{array}{l}\text { Foram criados quatro tópicos e estes } \\
\text { utilizavam os mesmos títulos do livro, } \\
\text { porém não na ordem ali encontrada, o que } \\
\text { significa que foi possível, de certo modo, } \\
\text { sair do padrão fechado do impresso e } \\
\text { modificar a configuração do AVEA. }\end{array}$ \\
\hline 3 & $\begin{array}{l}\text { Foram criados cinco tópicos, igual ao } \\
\text { número de capítulos do livro. }\end{array}$ & $\begin{array}{l}\text { Foram criados cinco tópicos, iguais ao } \\
\text { livro texto e na mesma ordem. }\end{array}$ \\
\hline 4 & $\begin{array}{l}\text { Não contempla todos os capítulos } \\
\text { dispostos no livro. Dos onze que compõem } \\
\text { o livro, apenas quatro transformaram-se } \\
\text { em tópicos. }\end{array}$ & $\begin{array}{l}\text { Foram criados três tópicos que } \\
\text { correspondem às três unidades centrais do } \\
\text { conteúdo da disciplina. }\end{array}$ \\
\hline 5 & $\begin{array}{l}\text { Foram criados três tópicos, condensando } \\
\text { alguns capítulos do livro. }\end{array}$ & $\begin{array}{l}\text { Também foram criados três tópicos, porém } \\
\text { estes foram intitulados por unidades I, II e } \\
\text { III que sugeriram a leitura dos capítulos do } \\
\text { livro, porém não na mesma seqüência. }\end{array}$ \\
\hline
\end{tabular}


Em todas as disciplinas pesquisadas encontramos "Fóruns gerais" e "Fóruns para atividades de aprendizado" por serem parte do modelo Moodle/UAB/UFSC e os cursos poderem criar tópicos de discussão nestes dois grandes grupos. Na "Tabela 4" vemos uma comparação entre os dois semestres pesquisados. Chama a atenção que apenas na "Disciplina 5" não houve um aumento no número dos fóruns criados. Nas outras, parece ter havido uma "descoberta" dessas ferramentas, considerando o aumento expressivo na segunda edição. No caso da criação de fóruns, não há interferência do número de pólos mas sim uma alteração nos espaços comunicacionais, ou seja, na reedição, os professores e tutores buscaram abrir mais possibilidades de expressão para os alunos.

Tabela 4 - Quantidade de fóruns criados em 2008-1 e 2009-2

\begin{tabular}{|c|c|c|c|c|c|}
\hline Edição/Disciplina & $\mathbf{1}$ & $\mathbf{2}$ & $\mathbf{3}$ & $\mathbf{4}$ & $\mathbf{5}$ \\
\hline $\mathbf{2 0 0 8 - 1}$ & 10 & 5 & 2 & 3 & 9 \\
\hline $\mathbf{2 0 0 9 - 2}$ & 26 & 8 & 7 & 13 & 6 \\
\hline
\end{tabular}

O criador do fórum é responsável por delimitar como ele vai ser desenvolvido, definindo quem vai ter permissão de participar daquele espaço e ainda qual é a expectativa do tipo de trabalho a ser desempenhado naquele ambiente. As possibilidades de formato de fórum do Moodle são as seguintes: a) uma discussão única com apenas um tópico, geralmente criado para um debate coletivo a partir de uma pergunta geradora; b) uma discussão marcada pela presença explícita do aluno para a tarefa, pois cada usuário pode iniciar apenas um tópico; c) fórum geral livre de perguntas e respostas; d) fórum de perguntas e respostas, gerando várias discussões tanto em volta do mesmo tema, bem como sobre os mais variados assuntos. $\mathrm{O}$ formato dos fóruns vai assim influenciar a quantidade de tópicos (ou postagens) gerados em cada um deles. Na "Tabela 5" vemos uma comparação entre os dois semestres pesquisados em termos de quantidade de tópicos. A quantidade de tópicos pode estar relacionada ao número de alunos (se estes quadruplicam, deveriam quadruplicar os tópicos publicados). Mas essa relação não pode ser direta já que o tipo de participação aberta ao aluno (por exemplo, o fórum que só permite um tópico) influencia no valor final. Da mesma maneira, a qualidade do tópico não pode ser definida pela quantidade, pois uma pergunta geradora interessante pode gerar muitas respostas e mesmo outros tópicos criados por outros atores motivados por ela. $\mathrm{O}$ autor do tópico, no entanto, pode ser um indicativo de participação dos atores dentro da disciplina, pois marca a presença do enunciador no AVEA. Por exemplo, o fato de na maioria das disciplinas haver uma quantidade menor de tópicos criados por professores demonstra que estes têm sua voz colocada em menos momentos.

Tabela 5 - Quantidade de tópicos em 2008-1 e 2009-2

\begin{tabular}{|c|c|c|c|c|c|}
\hline Edição/Disciplina & $\mathbf{1}$ & $\mathbf{2}$ & $\mathbf{3}$ & $\mathbf{4}$ & $\mathbf{5}$ \\
\hline $\mathbf{2 0 0 8 - 1}$ & 21 & 9 & 27 & 20 & 308 \\
\hline $\mathbf{2 0 0 9 - 2}$ & 38 & 36 & 34 & 82 & 176 \\
\hline
\end{tabular}

Na tabela 5 vemos que a "Disciplina 4" apresenta um diferencial em relação às demais. É a única em que o professor se destacou como autor dos tópicos. Nela houve um total de 82 tópicos criados. Destes, 24 foram criados pelo professor. Os tutores criaram 13 tópicos e os estudantes 46. Portanto se observa nesta disciplina a intensa participação dos estudantes e do professor. No item "número de postagens (tópicos + comentário)" os estudantes se destacam novamente com 375 postagens e logo após surgem os tutores com 216 postagens, o que indica que mesmo tendo criado 
poucos tópicos (13) em relação aos estudantes e professores, eles mediaram o processo de aprendizagem por meio de resolução de dúvidas. E para concluir, da mesma maneira que na tabela anterior, apenas na "Disciplina 5" não houve um aumento no número de tópicos criados, pelo contrário, estes foram diminuídos quase pela metade. No relatório anterior destacamos a discrepância do número de postagens na "Disciplina 5" em relação às demais disciplinas do curso. Ela é justificada em parte, devido ao caráter de seu conteúdo de trabalho, o qual tinha como um de seus principais objetivos pedagógicos, o de capacitar os estudantes para o uso das ferramentas no AVEA. Uma hipótese levantada é a de que diante deste foco de estudos, os estudantes sentiam-se mais a vontade para participar nas discussões sugeridas pelos "fóruns" disponibilizados neste ambiente específico.

A "Tabela 6" mostra a distribuição da autoria dos tópicos por professores, tutores e estudantes. Chama atenção a pequena participação dos professores na criação dos tópicos, que é zero em duas disciplinas, enquanto mostra o papel fundamental de mediação pedagógica dos tutores no AVEA. Na disciplina 2, o tutor publicou 32 tópicos contra quatro dos alunos e na disciplina 3 há uma inversão, o tutor publicou seis contra 28 postagens dos alunos. Mas se considerarmos que o número de tutores é quatro por disciplina, ainda temos um número muito pequeno de postagens de agentes que poderiam estar acompanhando e dando mais retornos aos alunos. A disciplina 5 tem uma grande participação dos alunos, o que mais uma vez mostra seu caráter interativo e de experimentação das ferramentas do AVEA.

Tabela 6 - Distribuição de autoria da disciplina em 2009-2

\begin{tabular}{|c|c|c|c|c|c|}
\hline Autores/Disciplina & $\mathbf{1}$ & $\mathbf{2}$ & $\mathbf{3}$ & $\mathbf{4}$ & $\mathbf{5}$ \\
\hline Professor & 5 & 0 & 0 & 24 & 10 \\
\hline Tutor & 23 & 32 & 6 & 13 & 17 \\
\hline Estudantes & 10 & 4 & 28 & 46 & 147 \\
\hline Total de postagens & 38 & 36 & 34 & 83 & 174 \\
\hline
\end{tabular}

A "Tabela 7" mostra o número de postagens nos fóruns feitas por professores, tutores e estudantes e que considera tanto os tópicos como os comentários. Chama atenção a pequena participação dos professores na criação das postagens, que mostra o papel fundamental de mediação pedagógica dos tutores no AVEA. Se considerarmos que os professores podem iniciar discussões quando criam os tópicos, podemos inferir que o trabalho de acompanhamento da discussão e ofeedback para essa participação intensa dos alunos não fez parte de seu trabalho a distância. Já o trabalho dos tutores nas disciplinas 1 e 3 foi baixo comparado com os outros colegas. A disciplina 5 e a 2 tiveram uma alta quantidade de postagens de alunos, indicando uma interatividade alta deles com o AVEA.

Tabela 7 - Distribuição da quantidade de postagens da disciplina em 2009-2

\begin{tabular}{|c|c|c|c|c|c|}
\hline Autores/Disciplina & $\mathbf{1}$ & $\mathbf{2}$ & $\mathbf{3}$ & $\mathbf{4}$ & $\mathbf{5}$ \\
\hline Professor & 20 & 15 & 9 & 24 & 24 \\
\hline Tutor & 71 & 275 & 69 & 216 & 135 \\
\hline Estudantes & 133 & 895 & 134 & 375 & 1102 \\
\hline Total de postagens & 224 & 1185 & 212 & 615 & 1261 \\
\hline
\end{tabular}

$\mathrm{Na}$ "Figura 1", vemos como a distribuição de postagens se apresentou na pesquisa anterior, em 2008-1. Os números mostram que as disciplinas tiveram um acréscimo grande de participação dos estudantes. Mesmo se considerarmos que tais dados precisariam ser multiplicados por quatro pelo acréscimo de pólos, a participação 
em todas as disciplinas foi maior que isso, menos na disciplina 5 que teve uma pequena redução. Muitas são as inferências possíveis diante de tais dados quantitativos. Podemos listar pelo menos duas delas: as estratégias utilizadas pelos profissionais envolvidos podem ter alcançado maior êxito frente ao desafio de incitar a participação dos alunos ou esses números pode representar um maior letramento digital por parte dos alunos em termos de facilidade e práticas de uso do Moodle.

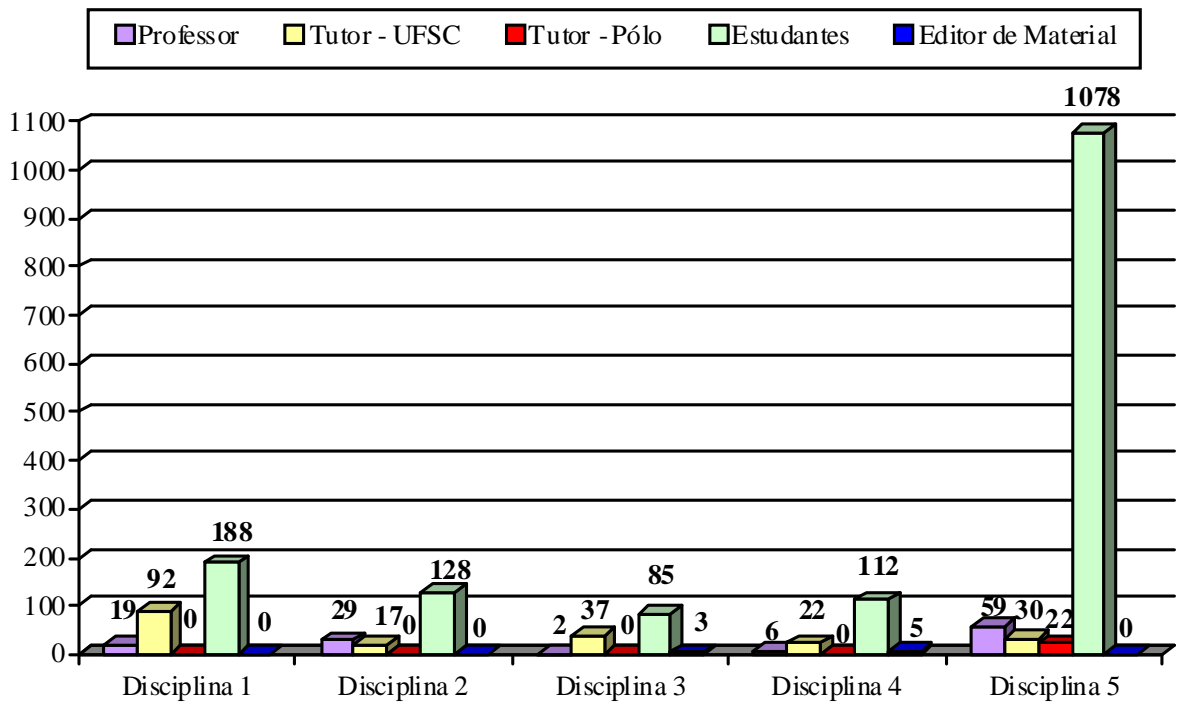

Figura 1 - Número de postagens de cada grupo de participantes nos fóruns disponibilizados no AVEA das disciplinas do "Curso de Licenciatura X" durante o primeiro semestre do curso (2008.1)

\section{CONCLUSÕES}

Podemos dizer que nossos dados mostram uma interessante evolução da $\mathrm{EaD}$ na UFSC. Tal constatação se faz pertinente após compararmos duas ofertas das mesmas disciplinas em períodos distintos. Fizemos uma análise quantitativa a fim de perceber se as discussões que ocorrem no AVEA, especialmente dentro dos fóruns das disciplinas, contribuem na promoção da interação entre professores, tutores e alunos com vistas à aprendizagem dos conteúdos curriculares. $\mathrm{O}$ intento foi o de perceber indícios sobre a utilização do fórum, se tem propiciado ou não a participação dos alunos envolvidos no processo.

O estudo mostrou que o papel do tutor a distância na UAB/UFSC consolidase como fundamental na mediação pedagógica considerando sua crescente participação nos meios analisados. Fato que pode indicar delegação de responsabilidade maior aos tutores, em comparação àquelas que inicialmente haviam sido planejadas para esses agentes. Uma hipótese seria que no quesito interação e mediação pedagógica realizadas nos ambientes virtuais de ensino e aprendizagem são os tutores os principais responsáveis, enquanto o professor, a quem também competia tal função, parece estar cada vez mais distante, ao menos em termos de presença escrita via AVEA, na relação com os alunos.

Positivamente, houve uma maior participação dos alunos nos fóruns do AVEA, se compararmos as duas edições. Esse fato pode suscitar algumas hipóteses tais como a existência de mudanças nas estratégias interativas lançadas pelos profissionais 
envolvidos ou que os novos estudantes podem ter um domínio maior das ferramentas digitais, o que facilitaria suas participações.

Contudo percebemos que o estudo quantitativo não é suficiente para entender realmente como interagem professores e tutores com os alunos. Por criarem mais fóruns e tópicos que os professores não necessariamente são os tutores mais responsáveis pela disciplina, o que levaria à pergunta do que e de quanto seria essa "responsabilidade". Tampouco conhecemos pelos números quais foram suas estratégias a fim de suscitar a maior participação dos estudantes dentro dos ambientes virtuais.

Por essa razão, estamos desenvolvendo em outro projeto, um estudo que pretende continuar investigando essas questões, escolhendo como enfoque $\mathrm{o}$ aprofundamento da análise, trabalhando diretamente nos diálogos encontrados nos fóruns de aprendizagem. Com experiências como essas, pretendemos esclarecer muitas questões, dúvidas e obter novos insights sobre a EaD que está sendo feita no dia-a-dia em uma das instituições da Universidade Aberta do Brasil.

\section{Agradecimentos}

Agradecemos ao CNPq pela bolsa produtividade em pesquisa concedida à Dulce Márcia Cruz e pelas bolsas de iniciação científica PIBIC/UFSC concedidas às alunas Mônica Grumiché e Mônica Riechel que fizeram o levantamento dos dados aqui discutidos.

\section{Referências Bibliográficas}

ALONSO, K. M. Tecnologias da informação e comunicação e formação de professores: sobre rede e escolas. Revista Educação e Sociedade, Campinas, v. 29, n.104, p.747768, out. 2008. Disponível em: <http://www.cedes.unicamp.br>. Acesso em: 28 ago. 2009.

BELLONI, M. L. Educação a Distância. Campinas: Autores Associados, 1999.

CRUZ. D. M. Mediação pedagógica e formação docente para a EaD: comunicação, mídias e linguagens na aprendizagem em rede. In: DALBEN, A.; DINIZ, J.; LEAL, L.; SANTOS, L. (Org.). Coleção Didática e prática de ensino: convergências e tensões no campo da formação e do trabalho docente. Belo Horizonte: Autêntica, 2010. p. 333-353. (Volume 2)

CRUZ, D. M.; GRUMICHÉ, M. C. D.; SILVA, P. R. F. Mídias e linguagem (ns) na EaD: um estudo da mediação pedagógica nos cursos a distância da UAB/UFSC. Relatório de pesquisa, 2010.

CRUZ D. M.; MARTINS, A. S. A EaD nas licenciaturas UFSC/UAB: um estudo da comunicação e das interações na disciplina de Introdução a Educação a Distância. Contemporânea. Salvador, v.6, p 1-31, 2008.

GUTIÉRREZ, F.; PRIETO, D. A Mediação Pedagógica - Educação a Distância alternativa. Campinas: Papirus, 1994.

MILL, D. R. S. et al. O desafio de uma interação de qualidade na educação a distância: o tutor e sua importância nesse processo. Cadernos da Pedagogia. UFSCar Online, ano 02, v. 02, n.04, p. 112-127, ago/dez. 2008. Acesso em: <http://www.cadernosdapedagogia.ufscar.br/index.php/cp/article/viewFile/106/63> Acesso em: 30 mai 2011.

UNIVERSIDADE FEDERAL DE SANTA CATARINA. Guia do Tutor UAB/UFSC. 2009. mimeo. 